\title{
Four key questions that identify severe disability
}

\author{
Jean Fooks
}

\begin{abstract}
Background-Six hundred and four surviving children aged 2 years, who had been entered into a neonatal trial of fresh frozen plasma on the incidence of intraventricular haemorrhage, were grouped into four categories of disability based on a review by a full paediatric assessment. A 29 item questionnaire completed by the children's health visitors was used to group the children into the same categories.

Aims-To explore whether severe disability could be identified by using only a few of the 29 questions.

Method-The sensitivity and specificity of individual questions were used first to find the subset of questions that best identified children with severe disability. The efficacy of the four most useful questions was tested in a separate cohort of 105 children for whom health visitors had completed questionnaires at the age of 2 years, and who had similarly been assessed by a paediatrician.

Results-In the original trial cohort, the four questions correctly identified 56 of the 61 children with the most severe disabilities as assessed by the paediatrician, and seven children were falsely identified as being severely disabled. In the second cohort, the four questions correctly identified six of the seven children classified as severely disabled by the paediatrician, with no false positives. Conclusion-If four such questions were included in routine child information systems at age 2 years, it might be possible to obtain useful data on the prevalence of severe disability in children.

(Arch Dis Child 1999;80:67-68)
\end{abstract}

Keywords: disability; outcome; questionnaire

Table 1 Characteristics of four questions used to identify severe disability

\begin{tabular}{lcccc}
\hline Question & Sensitivity & Specificity & PPV & NPV \\
\hline $\begin{array}{l}\text { Motor } \\
\text { Can the child not walk five steps alone } \\
\begin{array}{l}\text { without holding on to anyone or } \\
\text { anything? }\end{array}\end{array}$ & $83.6 \%$ & $98.9 \%$ & $91.1 \%$ & $97.8 \%$ \\
$\begin{array}{l}\text { Developmental/cognitive } \\
\text { Overall do you think the child is behaving } \\
\text { in the same way as a child who is less } \\
\text { than 1 year old? }\end{array}$ & $61.7 \%$ & $99.8 \%$ & $97.4 \%$ & $95.1 \%$ \\
$\begin{array}{l}\text { Vision } \\
\text { Would you say the child sees very little or } \\
\text { not at all? }\end{array}$ & $13.1 \%$ & $100.0 \%$ & $100.0 \%$ & $89.4 \%$ \\
$\begin{array}{l}\text { Hearing } \\
\text { Would you say the child has severe hearing } \\
\text { difficulty, or has some difficulty with } \\
\text { hearing and has been fitted with hearing } \\
\text { aids? }\end{array}$ & & & & \\
\end{tabular}

$\mathrm{PPV}$, positive predictive value; NPV, negative predictive value.
Now that babies born prematurely or with serious perinatal problems are increasingly likely to survive, the presence or absence of disability in those survivors is often the outcome to be measured in trials of new treatments. For example, in the recent UK trial of extracorporeal membrane oxygenation (ECMO), ${ }^{1}$ the primary end point was survival without severe disability at the age of 1 year. However, the conventional method involves full neurodevelopmental assessment and physical examination which, for large numbers of children, can be both expensive and impracticable. Questionnaires developed as an alternative method have tended to be long and detailed; the study reported here explored the possibility of using four key questions to identify children with severe disability.

\section{Methods}

The Northern Neonatal Nursing Initiative (NNNI) Trial Group in the Northern region of the UK, investigating the use of early prophylactic fresh frozen plasma to reduce the risk of intraventricular haemorrhage in babies born more than eight weeks premature, chose survival without severe disability to age 2 years as the main outcome measure. ${ }^{2}$ All 604 children in the trial who survived to age 2 were assessed by a single developmental paediatrician who categorised a child as severely disabled if any of the following were present: cerebral palsy with significant functional loss, overall developmental quotient (DQ) more than two standard deviations below the mean (78 for this group of preterm babies), blindness or partial sight, or sensorineural hearing loss and use of a hearing aid.

Before the paediatrician assessed the child at age 2 years, each child's health visitor was asked to complete a 29 item questionnaire. This asked a range of questions on functional ability, questions on problems with vision or hearing, and finally for an estimate of overall apparent developmental age. Health visitor answers were available for 498 of the 604 NNNI trial survivors. A comparison of the paediatric assessment with the questionnaires has been published. ${ }^{3}$

Our study first calculated the sensitivity and specificity of each question in identifying children with severe disability. Combinations of two or more questions were then investigated until the set of questions was found that best identified those children categorised by the paediatrician as severely disabled.

The validity of this combination of questions was then tested on a group of 105 children born in the region from 1990 to 1991 but not 
Table 2 Comparison of paediatric assessment of the presence of severe disability with four questions to health visitors in the NNNI trial

\begin{tabular}{lrcr}
\hline & \multicolumn{3}{c}{ Paediatric assessment } \\
\cline { 2 - 4 } Four questions to health visitors & Present & Not present & Total \\
\hline Present & 56 & 7 & 63 \\
Not present & 5 & 430 & 435 \\
Total & 61 & 437 & 498 \\
\hline
\end{tabular}

Table 3 Comparison of paediatric assessment of the presence of severe disability with four questions to health visitors in the further cohort

\begin{tabular}{llcr}
\hline & \multicolumn{3}{l}{ Paediatric assessment } \\
\cline { 2 - 4 } Four questions to health visitors & Present & Not present & Total \\
\hline Present & 6 & 0 & 6 \\
Not present & 1 & 98 & 99 \\
Total & 7 & 98 & 105 \\
\hline
\end{tabular}

enrolled into the NNNI trial, for whom the same health visitor questionnaire had been used.

\section{Results}

Table 1 shows the four questions found to identify most effectively those children categorised as severely disabled by the paediatrician. Taken together to identify severe disability, the four question set had a sensitivity of 56 of 61 and a specificity of 430 of 437 (98.4\%) (table 2 ). Five children considered to have severe disability by the paediatrician were not identified from the responses to these four questions; one had a gastrostomy and severe feeding problems, the other four had overall developmental delay with DQs between 65 and 78 .

Of the 63 children classified as severely disabled by the responses to the four questions, seven were not so classified by the paediatrician. Five of these seven children were reported by the health visitor as unable to take five steps alone, a sixth child was thought to be behaving at below 1 year of age, and the seventh was thought to have severe hearing problems. Based on the four questions, the incidence of severe disability in the cohort at age 2 years was 63 of $498(12.7 \%)$, compared with 61 of 498 $(12.2 \%)$ based on the paediatrician's classification.

When tested on the further 105 children, only one child was wrongly classified using the health visitors' answers (table 3). This child had low vision, which was considered to be more severe by the paediatrician than by the health visitor.

\section{Discussion}

Using the answers from health visitors to four key questions at the age of 2 years, most of the children with severe disability were identified correctly. False negatives were accounted for mostly by children with a moderately low DQ (between 65 and 78) who, not surprisingly, were not considered by the health visitor to be behaving below a 1 year level. There were some false positives, most of whom were said by the health visitor not to be walking at the age of 2 years, although the paediatrician decided four of the five concerned could walk alone when he saw them. The discrepancy could well be explained by the time lapse between the health visitor's completion of the questionnaire and the paediatrician's visit. Late walking has been shown previously to be a useful marker for severe disability. ${ }^{4}$

Combining four key questions to screen for severe disability in this way appears to identify disabled children with considerable accuracy, whereas the sensitivity of any one question on its own is necessarily only applicable in that one domain. The agreement between health visitor and paediatrician on individual questions has been discussed elsewhere. ${ }^{3}$

This minimalist approach is not new. Data from the Newcastle survey of child development from 1960 to 1962 allowed identification of the small group of children "excluded from normal school" using four early developmental milestones. ${ }^{5}$ In addition, paediatricians working in Bangladesh have developed a 10 item questionnaire with some success. ${ }^{6}$

Asking a health visitor to give the answers to only four questions would probably encourage replies from those who felt too busy to fill in a 29 item questionnaire. However, they would need to be assured that their cooperation would provide useful information; the use of only four questions needs to be tested to ensure that they would be as reliable when used on their own as when forming part of a much longer questionnaire.

Overall, it seems that this approach might be useful in large randomised controlled trials in which the end point of interest is severe disability. This is of course an epidemiological approach and is not useful in clinical management. If, however, the four questions were included in the information recorded in the routine child health information systems at the age of 2 years, it could be used as a way of monitoring the rate of severe disability in the childhood population as a whole, or within birth weight groups.

I am grateful to colleagues who commented on earlier drafts. Particular thanks are due to the health visitors in the former Northern region who filled in all those questionnaires and to Dr W Tin who assessed all the children personally.

1 UK Collaborative ECMO Trial Group. UK collaborative randomised trial of neonatal extracorporeal membrane randomised trial of neonatal extracor
oxygenation. Lancet 1996;348:75-82.

2 The Northern Neonatal Nursing Initiative Trial Group. A randomized trial comparing the effect of prophylactic early fresh frozen plasma, gelatin or glucose on early mortality and morbidity. Eur $\mathcal{F}$ Pediatr 1996;155:580-8.

3 Fooks J, Fritz S, Tin W, et al. A comparison of two methods of follow-up in a trial of prophylactic volume expansion in preterm babies. Paediatr Perinat Epidemiol 1998;12:199216.

4 Johnson A, Goddard O, Ashurst H. Is late walking a marker of morbidity? Arch Dis Child 1990;65:486-7.

5 Neligan G, Prudham D. Potential value of four early developmental milestones in screening children for increased risk of Latwer retardation. Dev Med Child Neurol 1969;11: 423-31.

6 Zaman SS, Khan NZ, Islam S, et al. Validity of the "ten questions" for screening serious childhood disability: results from urban Bangladesh. Int $\mathcal{F}$ Epidemiol 1990;19: 613-20. 